\title{
Mining the Biomarker Potential of the Urine Peptidome: From Amino Acids Properties to Proteases
}

\author{
Fábio Trindade ${ }^{1, *}$, António S. Barros ${ }^{1}{ }^{\mathbb{D}}$, Jéssica Silva ${ }^{2}$, Antonia Vlahou ${ }^{3}$, Inês Falcão-Pires ${ }^{1}$, Sofia Guedes ${ }^{4}$, \\ Carla Vitorino ${ }^{5,6,7} \mathbb{D}$, Rita Ferreira ${ }^{4}$, Adelino Leite-Moreira ${ }^{1}{ }^{\mathbb{C}}$, Francisco Amado ${ }^{4}$ and Rui Vitorino ${ }^{1,2,4, * \mathbb{C}}$ \\ 1 UnIC —Cardiovascular Research and Development Centre, Department of Surgery and Physiology, \\ Faculty of Medicine, University of Porto, 4200-319 Porto, Portugal; asbarros@med.up.pt (A.S.B.); \\ ipires@med.up.pt (I.F.-P.); amoreira@med.up.pt (A.L.-M.) \\ 2 iBiMED—Department of Medical Sciences, Institute of Biomedicine, University of Aveiro, \\ 3810-193 Aveiro, Portugal; jessica.ferreira.da.silva.18@gmail.com \\ 3 Biotechnology Division, Biomedical Research Foundation of the Academy of Athens, 11527 Athens, Greece; \\ vlahoua@bioacademy.gr \\ 4 LAQV-REQUIMTE, Departamento de Química, Universidade de Aveiro, 3810-193 Aveiro, Portugal; \\ sguedes@ua.pt (S.G.); ritaferreira@ua.pt (R.F.); famado@ua.pt (F.A.) \\ 5 Faculty of Pharmacy, University of Coimbra, 3000-548 Coimbra, Portugal; csvitorino@ff.uc.pt \\ 6 Coimbra Chemistry Centre, Department of Chemistry, University of Coimbra, 3004-535 Coimbra, Portugal \\ 7 Center for Neurosciences and Cell Biology (CNC), University of Coimbra, 3004-504 Coimbra, Portugal \\ * Correspondence: ftrindade@med.up.pt (F.T.); rvitorino@ua.pt (R.V.)
}

\section{check for} updates

Citation: Trindade, F.; Barros, A.S.; Silva, J.; Vlahou, A.; Falcão-Pires, I.; Guedes, S.; Vitorino, C.; Ferreira, R.; Leite-Moreira, A.; Amado, F.; et al. Mining the Biomarker Potential of the Urine Peptidome: From Amino Acids Properties to Proteases. Int. J. Mol. Sci. 2021, 22, 5940. https://doi.org/ $10.3390 /$ ijms 22115940

Academic Editor:

Olga Golubnitschaja

Received: 30 April 2021

Accepted: 28 May 2021

Published: 31 May 2021

Publisher's Note: MDPI stays neutral with regard to jurisdictional claims in published maps and institutional affiliations.

Copyright: (c) 2021 by the authors. Licensee MDPI, Basel, Switzerland. This article is an open access article distributed under the terms and conditions of the Creative Commons Attribution (CC BY) license (https:// creativecommons.org/licenses/by/ $4.0 /)$.
Abstract: Native biofluid peptides offer important information about diseases, holding promise as biomarkers. Particularly, the non-invasive nature of urine sampling, and its high peptide concentration, make urine peptidomics a useful strategy to study the pathogenesis of renal conditions. Moreover, the high number of detectable peptides as well as their specificity set the ground for the expansion of urine peptidomics to the identification of surrogate biomarkers for extra-renal diseases. Peptidomics further allows the prediction of proteases (degradomics), frequently dysregulated in disease, providing a complimentary source of information on disease pathogenesis and biomarkers. Then, what does urine peptidomics tell us so far? In this paper, we appraise the value of urine peptidomics in biomarker research through a comprehensive analysis of all datasets available to date. We have mined $>50$ papers, addressing $>30$ different conditions, comprising $>4700$ unique peptides. Bioinformatic tools were used to reanalyze peptide profiles aiming at identifying disease fingerprints, to uncover hidden disease-specific peptides physicochemical properties and to predict the most active proteases associated with their generation. The molecular patterns found in this study may be further validated in the future as disease biomarker not only for kidney diseases but also for extra-renal conditions, as a step forward towards the implementation of a paradigm of predictive, preventive and personalized (3P) medicine.

Keywords: urine; peptides; proteases; peptidomics; degradomics; biomarkers; predictive, preventive and personalized (3P) medicine; molecular patterns; individualized patient profiling

\section{Introduction}

The peptidome refers to the whole set of low molecular weight (LMW) peptide elements in a sample. The peptidome is often viewed as a subset of the proteome since most polypeptides (generally with a molecular weight lower than $20 \mathrm{kDa}$ ) result from the cleavage of native proteins [1-3]. One of the key features of peptidomics, i.e., the analysis of the native peptidome, is studying endogenous proteolytic events while preserving information on post-translational modifications [4]. Proteolytic cleavage is an essential biological process for protein maturation, activation, and turnover (lysosomal and proteasomal degradation) [5]. The human degradome comprises over 550 proteases, categorized into five groups, according to the catalytic mechanism [6]: serine proteases, threonine 
proteases, aspartic proteases, cysteine proteases, and metalloproteases. Many disease states are associated with an unrestricted and abnormal progression of proteolysis [7], making proteases and peptides key molecular entities with value as biomarkers and potential therapeutic targets. Peptidomics and degradomics hold, thus, great interest in predictive, preventive and personalized medicine (3P) medicine, the new paradigm in the practice of medicine, encompassing both "health care" and "disease care", synergizing the advantages of several biomedical fields and cutting-edge technologies (such as mass spectrometry), through the collaboration of multidisciplinary teams [8].

There are many advantages of peptidomics over proteomics: (1) it can attain a larger number of disease-specific analytes, provided the generation of many peptides from a single parent protein, which results in improved discrimination; (2) it allows the study of the disease microenvironment, as peptides can cross endothelial barriers providing clinicallyrelevant biomarkers; (3) it is possible to extract information associated to proteolytic activity; (4) sample processing is much simpler, excusing enzymatic digestion and reducing intra-sample heterogeneity $[9,10]$.

Endogenous peptides have only recently received attention as their relevance in disease characterization has not been adequately acknowledged [10]. Analytical techniques related to the characterization of the LMW sub-proteome lacked sensitivity at the dawn of proteomics [11]. However, today, the combination of high-performance liquid chromatography or capillary electrophoresis with high resolution mass spectrometers, usually using time-of-flight analyzers, but also Orbitraps, provides the needed sensitivity for the identification of thousands of peptides. The developments in the analytical platforms for the analysis of the peptidome is beyond the scope of this paper, but the reader is referred to two excellent reviews by Schrader [12] and Latosinska et al. [9]. Another major hindrance in peptidomics research is the low abundance of peptides in some, but not all, biological samples [7]. Furthermore, the detection of LMW protein species might be hampered by the presence of highly abundant proteins in some biofluids, such as blood, thus requiring pre-fractionation or enrichment steps [13]. Some endogenous peptides can also be shared over several proteins, obfuscating their role in disease etiology [14]. Besides, they require complex bioinformatics pipelines for analysis [10].

\section{The Potential of Urine Peptidomics}

Urine is perhaps, of all biofluids, the one with greater potential in clinical peptidomics. Urinary proteins and peptides originate from the secretions of renal tubular epithelial cells, shedding of cells along the urinary tract, exosome secretion, and more importantly, from glomerular filtration of plasma $[15,16]$. Therefore, beyond the renal system's pathophysiological status, the urinary peptidome is influenced by systemic disturbances. Due to the high reabsorption levels by the epithelial cells lining on the proximal tubules, protein species in the tubular lumen are present in minimal quantities [5]. Thus, peptides dominate a relatively larger proportion of the proteome in urine as opposed to other biofluids. Finally, the urine peptidome is considered more stable than other peptidomes, such as blood, because the bulk of proteolytic events has already been completed within the bladder [5].

The particular clinical value of urine peptidome is reflected by several studies where putative biomarker panels have been developed based on urinary peptides, aiming at the non-invasive diagnosis, prognosis of specific diseases, or flagging the need of an intervention. Due to anatomical proximity, most studies have centered, thus far, on the potential of urine peptidome to uncover biomarkers for kidney or urogenital conditions [17]. For instance, peptidomics has been used for the investigation of renal system diseases such as for the prediction of chronic kidney disease (CKD) progression or remission [16,18], suggesting associations of multiple peptides, predominantly collagen fragments, with glomerular filtration and the processes of inflammation and repair [19]. Another example is the so-called CKD273 classifier, a panel composed of 273 urinary peptides that has been validated in multiple studies for early detection of CKD and monitoring progression $[18,20]$ and even recently used in a clinical trial for diabetic patient stratification and early detection 
of diabetic nephropathy [21]. Markoska et al. (2016) also studied peptidome alterations related to Autosomal dominant polycystic kidney disease (ADPKD) and acute kidney injury (AKI) and proposed a biomarker panel of $20 \mathrm{LMW}$ urine peptides for ADPKD and 39 for AKI [22]. These approaches have high clinical relevance as CKD progression does not present early warning signs of kidney damage [16], hence reliable tools for early detection are deemed necessary for timely and therapeutic intervention. The search for disease markers [14,23] resulted for instance, in a peptide classifier composed of 21 peptides for diabetic nephropathy $(\mathrm{DN})$ diagnosis showing a higher association with in situ glomerular lesions when compared to albuminuria (a commonly used biomarker in the clinics) [14]. Several authors also investigated DN using urinary peptidomics to unravel the disease pathophysiology mechanisms [24-29]. Urine peptidome is also an exciting study area for renal and genital cancers [17]. Based on the established link between lower urinary tract symptoms (LUTS) and prostate cancer (PCa), researchers have sought biomarkers able to differentiate between benign and malignant PCa in patients with a diagnosis of LUTS [30]. Potential biomarkers for bladder cancer have been intensively probed through urine analysis [10]. Furthermore, peptide profiling was proposed for the accurate prognosis and diagnosis of renal cell carcinoma (RCC) subtypes: papillary, chromophobe, and clear cell RCC [31].

Apart from the proven value of urine peptidomics in developing new diagnostic tools for diseases afflicting the renal-urogenital axis, the diagnostic/prognostic potential of urine peptidomics extends to other systemic conditions. Endogenous peptides from other sources may cross the endothelial barrier and be cleared out by the renal system, thus being surveyed through urine analysis $[16,32,33]$. For example, a set of 47 urinary peptides (mostly collagen-related) was found relevant to systemic lupus erythematosus progression and are candidates for a biomarker diagnosis panel [34]. In turn, 112 urinary peptides (also collagen-related) and 32 proteases (matrix metalloproteases, MMPs, and cathepsins) were associated with the molecular mechanisms of aging [35]. Besides, a 96-peptide classifierthe heart failure predictor-was proposed to stratify the risk for left ventricular heart failure [36]. It should be highlighted that urine's intrinsically stable proteolytic activity makes this biological matrix particularly suited to study proteolysis [32], a hallmark of several conditions, such as metastasizing cancer. On top of peptides, proteases predicted and validated from urine peptidome may improve our perception of the disease and contribute with new insight and tools for the diagnosis/prognosis.

Clinical interest in urine peptides is mounting, particularly as surrogate biomarkers for chronic conditions, such as those directly afflicting the kidney. With the growing number of studies following a urine peptidomics approach, it is mandatory to evaluate the data published thus far to typify the major findings in this field, aiming to accelerate the introduction of urine peptides as biomarkers in clinical practice. By doing an unbiased collection of all studies until today, mining the accessible peptidome data, and comparing the peptidome profile across different disease classes, we aimed to highlight the diseaseassociated peptide markers currently established. Furthermore, by exploring peptides' physical properties, such as mass, length, or isoelectric point, we hope to disclose disease class patterns that may be of diagnosis relevance upon a simple urinalysis. Finally, considering the urine's unique proteolytic environment, which deems the urine peptide collections more stable than in any other biofluid, we might predict potentially dysregulated proteases in the various conditions, hopefully pinpointing new biomarkers to be added to the set of urinary peptides.

\section{Brief Methods}

\subsection{Literature Search and Data Mining}

A literature data research was conducted using the PubMed database up to July 2020, employing the combination of the following keywords: ("peptidome" OR "peptidomic" OR "peptidomics") AND ("urine" OR "urinary"). This search retrieved 132 articles. After excluding reviews, articles written in languages other than English and not directly related 
to the urinary peptidome, and after including some articles found by cross-referencing the identified papers, a final set of 54 was obtained (Table S1). These studies covered over 30 diseases, categorized in nine main classes, from the most to the least frequent: renal, cardiovascular, cancer, autoimmune, metabolic, infections, mental, bowel, and respiratory diseases. Not surprisingly, studies on urinary peptidome in renal diseases represent the largest fraction $(\sim 36 \%)$, closely followed by those on cardiovascular abnormalities $(\sim 20 \%)$.

Each study was mined to extract the pathology, disease class, general information about the discovery and validation phases (e.g., number of subjects, number of identified proteins and peptides, number of sequenced differentially expressed peptides, and number of sequenced signature peptides), methodological approach (identification strategy, sequencing strategy, and biomarker assessment algorithm) and, if present, the details on the peptide panel performance in terms of C-statistics. The extracted data is available in Table S1 and represents all studies performed so far on urinary peptidomics, to the best of our knowledge. Then, to probe the hypothetical diagnostic nature of the peptides across all conditions/disease classes, the peptides displaying a potential discrimination power amongst conditions were selected from the discovery phase or from the validation phase, for instance, in the cases where the former were not available. In any case, the pool of peptides selected for analysis is marked as green in the Table S1, and the selection is justified in Table S2. The peptide sequences, together with the start and end amino acid positions and the source proteins (UniProt code and gene name), can be found in Table S3. Herein, only successfully sequenced peptides, showing relevant differences between the control condition and the disease, and whose sequence information was reviewed, according to UniProt, were considered. For comparison to the healthy peptidome, we had available two studies. Siwy et al. [37] could identify a total of 953 peptides, from over 13,000 urine samples belonging to either ill or control subjects. However, controls included both healthy subjects and other conditions not directly related to the disease at scope, which hindered the extraction of the "healthy" peptidome. Therefore, we could not use this dataset. Instead, we sourced the data of Di Meo et al. [38], the most detailed data on the human natural urine peptidome released and available to date. Moreover, this dataset presented over 4500 sequenced peptides, reflecting perhaps the utilization of a more advanced mass spectrometer, the $\mathrm{Q}$ exactive $\mathrm{e}^{\mathrm{TM}}$ instrument, not implemented at the time of the former publication (2011). The sequence information and parent proteins can be consulted in Table S4. As before, the peptides were selected only if they were derived from a reviewed protein sequence, according to UniProt.

\subsection{Statistical and Bioinformatics Analyses}

All peptide sequences associated with a disease were given a unique peptide ID and were associated to a specific condition, classified in nine major classes: autoimmune, bowel, cancer, cardiovascular, infection, mental, metabolic, renal, and respiratory diseases (see Table S3). Similarly, all peptides identified in the Di Meo et al. [38] dataset were given a unique peptide ID and associated to a single class: health.

Aiming to identify peptide signatures for each condition, we performed network analysis using Cytoscape (v.3.8.2). Briefly, an interaction table was created (Table S5), listing all disease-peptide associations, which was then imported to the Cytoscape environment. The conditions were defined as source nodes and the sequences as target nodes. We then mapped the nodes according to the degree, i.e., the total number of interactions, to single out those peptides associated with a unique condition (degree $=1$ ). The node size was defined in descending order of the degree (with a bypass for the conditions themselves) to highlight those peptides with higher potential to create a disease fingerprint. The network analysis table was then exported, and the signature peptides obtained by filtering those of degree 1.

The signature peptides obtained through network analysis were then studied regarding their single amino acid composition and physical-chemical properties, using $\mathrm{R}$ statistical software built-in functions and the package 'Peptides' [39]. For this analysis we only con- 
sidered disease classes with at least 20 unique peptides associated. As a reference, we used the complete set of peptides identified in healthy individuals [38]. First, we performed contingency analysis of the amino acid composition. Then, we assessed the percentage of nine amino acid groups, showing different physical-chemical properties: acidic, aromatic, basic, charged, hydrophobic, polar and charged, polar non-charged, small, and tiny amino acids. Finally, we calculated the sequence length (function "lengthpep"), molecular weight (function " $\mathrm{mw}^{\prime}$ ), isoelectric point (function " $\mathrm{II}^{\prime}$ ), grand average of hydropathy (GRAVY) score (function "hydrophobicity"), in addition to the probability of antimicrobial activity (using the Collection of Antimicrobial Peptides (CAMP R3)'s prediction tool available on http:/ /www.camp3.bicnirrh.res.in/, accessed on 23 July 2020) and the content in proline, an amino acid with special properties.

Provided the possibility to study the urine degradome, based on its peptidome, we used Proteasix web tool, an open-source peptide-centric tool, to compute the cleavage probability of native proteins originating the urinary peptides (Tables S3 and S4) by a wide array of proteases [40]. This algorithm was applied to both the disease (3014) and the health peptides (3767), aiming at predicting the most enriched proteases in all conditions and disease classes, whose urine peptidome has been characterized to date. In this analysis, both N-terminal and C-terminal cleavages were considered, but exclusively by human proteases. Proteasix predicts proteases based on the known target sequence specificity, according to the peptidase database MEROPS [41]. The list of predicted proteases was then imported to $\mathrm{R}$ and the enrichment over the health dataset was calculated. A hypergeometric test was applied, and the Bonferroni method was used to correct for multiple testing. An adjusted $p$-value $<0.05$ was considered significant.

\section{Results and Discussion}

\subsection{The Urinary Peptidome as a Road to Defining Molecular Disease Signatures}

From the human urinary peptidome studies collected and mined, we extracted a total of 3014 differentially expressed peptides in numerous conditions affecting the main physiological systems, such as the renal, cardiovascular, and metabolic systems. Following the volume of studies in those areas, not surprisingly, a higher number of peptides and proteins were found associated with renal (1682 from 159 proteins) and cardiovascular (890 from 159 proteins) diseases (Figure 1). Although we only included one study unequivocally reporting the healthy urine peptidome, the number of sequenced peptides is comparable to the sum of disease peptides: 3765 unique peptides were gathered to represent the healthy urinary peptidome [38]. A quick comparison between disease and health proteome and peptidome shows that while $30 \%$ of the proteins (88 out of 294) dysregulated in disease were present in the comprehensive health dataset (Table S4), only $17.4 \%$ of the dysregulated of the peptides (203 out of 1166) were also sequenced in the healthy patients. This supports the notion that biomarkers panels composed of peptides can more easily discriminate a disease than a protein panel. Although encouraging, these statistics should be interpreted with caution, since the peptides have been collected from different studies, using diverse experimental approaches (though, not as much regarding sample preparation) and data analysis strategies. Nonetheless, this first analysis: (i) corroborates the vision of urine as an important reservoir of disease biomarkers; (ii) demonstrates the superiority of urine peptidomics to proteomics in biomarker discovery and (iii) suggests that urine's proteolytic environment underlies the greater diversity of surrogate peptide markers compared to protein markers. 

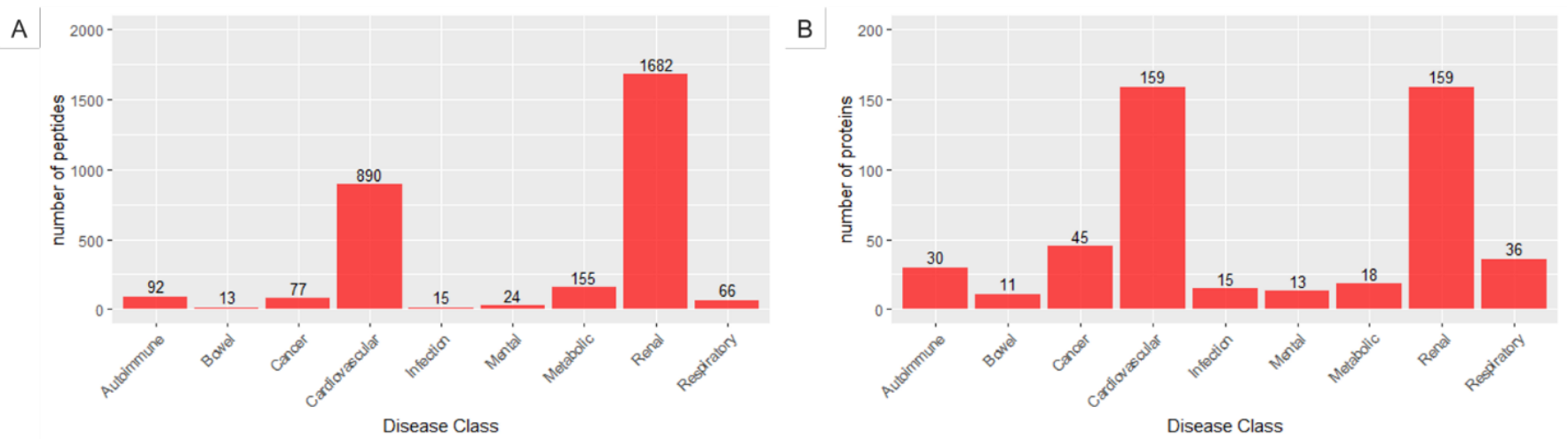

Figure 1. Distribution of unique peptides (A) and proteins (B) across the different disease classes.

Aiming to uncover and identify peptides with biomarker ability for the 37 conditions studied (spread across nine major classes), a network analysis was performed using Cytoscape. This network can be explored online at NDEx (v.2.5.0) platform https: / public. ndexbio.org/\#/network/2c846129-a774-11eb-9e72-0ac135e8bacf?accesskey=5ff3875974d1 53a2b6a8a6bd64988237497a19118713529bb4e9a149ed435960. The conditions are presented as red nodes (source) and the peptide sequences as blue nodes (target). The peptide was mapped according to the degree so that those of first degree (the most specific) were shown as more prominent nodes. As shown by the density of larger blue nodes in the network's outer layer, there are many peptides with the potential of becoming a signature for many of these diseases-644 in total. This list is provided in Table S6. Beyond being a reservoir of molecular markers for kidney conditions, such as chronic kidney disease (with 43 specific peptides) or type 2 diabetic nephropathy (with 54 specific peptides), this exploratory analysis illustrates that urine is an important source of putative biomarkers for diseases afflicting extra-nephrotic tissues/organs, namely the heart (e.g., heart failure with reduced ejection fraction with 11 specific peptides), the lungs (e.g., chronic obstructive pulmonary disease with 38 specific peptides) or even the bowel (e.g., necrotizing enterocolitis with eight specific peptides).

\subsection{Can We Distinguish Disease Classes by Peptides' Physical-Chemical Properties?}

Being the most relevant disease-specific urine peptides probed to date, not only regarding health but also considering all other conditions whose the urine peptidome has been investigated, we explored their physical properties in different disease classes hoping to disclose distinctive molecular traits among them. Due to the low representation of some classes in terms of peptides, we only considered the following classes: autoimmune, cancer, cardiovascular, renal, and respiratory diseases. Considering that the amino acids confer the first level of complexity of peptides and are the first determinants of the physical, chemical, and biological properties of peptides, it is not implausible to hypothesize that the amino acid composition, alone, might distinguish different disease classes. Therefore, we started by breaking down the composition of "signature" peptides into the 20 amino acids (Figure 2) to look at potential differences in the primary sequence of peptides assigned to the various classes. Interestingly, autoimmune peptides are characterized by the lack of Cys and Met. Peptides associated with respiratory diseases also lack Cys. One could argue that such an underrepresentation of Cys in autoimmune and respiratory disorders might be an artifact due to the reduction and alkylation of the peptides, but this was not the case. Only in two unrelated studies, one in the setting of renal cell carcinoma [42] and the other in type 1 diabetes mellitus [43] researchers have opted to modify cysteines. 


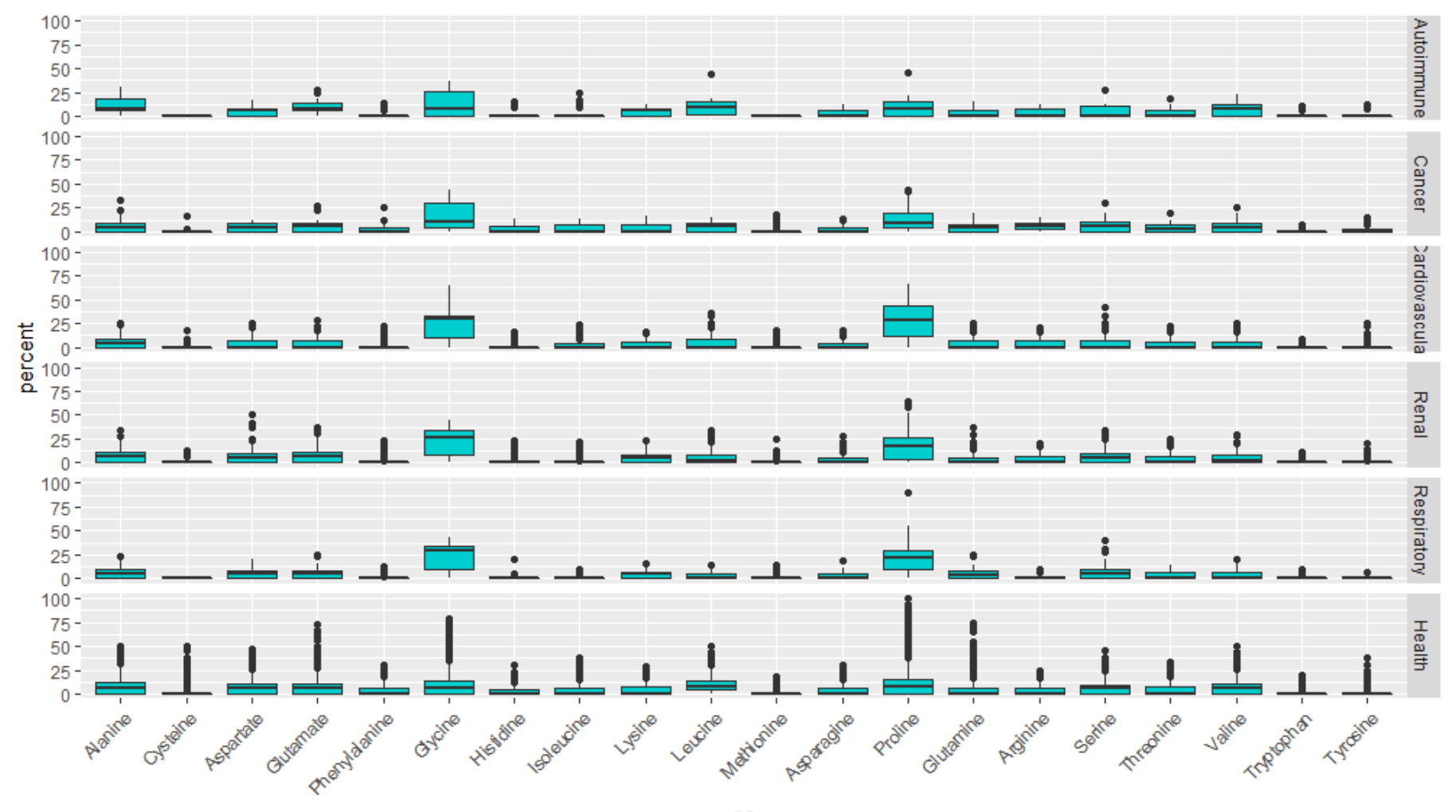

aа

Figure 2. Amino acid composition of each disease class' "signature" peptides.

More evident is, perhaps, the higher content in Gly of the disease-associated peptides. A new hypothesis emerges, whereby, the relative increase of Gly on urine peptidome indicts the presence of a disease. Also noticeable is the higher levels of Pro in peptides more specific to cardiovascular and respiratory conditions, suggesting that this amino acid might be a nonspecific marker of these disease classes. Indeed, Alvarez-Llamas et al. [44] have already described the arginine and proline metabolism dysregulation in a leporine model of atherosclerosis after characterizing the urine metabolome.

After examining the amino acids individually, we categorize them according to their physical-chemical properties: acidic, aromatic, basic, charged, hydrophobic, polar and charged, polar non-charged, small, and tiny amino acids (Figure 3). This analysis uncovered a pattern in peptides associated with cardiovascular conditions: peptides are mainly composed of small and more hydrophobic amino acids, with low representation of polar and/or charged amino acids.

Finally, we analyzed the distribution of peptides in health and disease sets concerning relevant features and properties of the peptides, such as the sequence length, molecular weight, isoelectric point, GRAVY score, and the content in Proline. As shown in Figure 4, there are no differences in the distribution of peptides according to their antimicrobial potential, except maybe for a small group of peptides associated to autoimmune disorders, showing a high probability of antimicrobial activity. It would be expected a high percentage of peptides with predicted antimicrobial peptides in urine from patients with infections, however we did not include the peptides associated to infections in this analysis, given the low number of specific peptides found (14). No apparent major changes in the distribution of the peptides regarding the isoelectric point could be seen, as well. Concerning the GRAVY score, a commonly used metric to evaluate a peptide's hydrophobicity, a very sharp distribution of peptides around -1 (hydrophilic peptides) was observed for respiratory diseases. This might be explained by the fact that hydrophilic peptides are more easily transported in the blood from extrarenal tissues to the kidneys and then more easily filtered off to urine. 


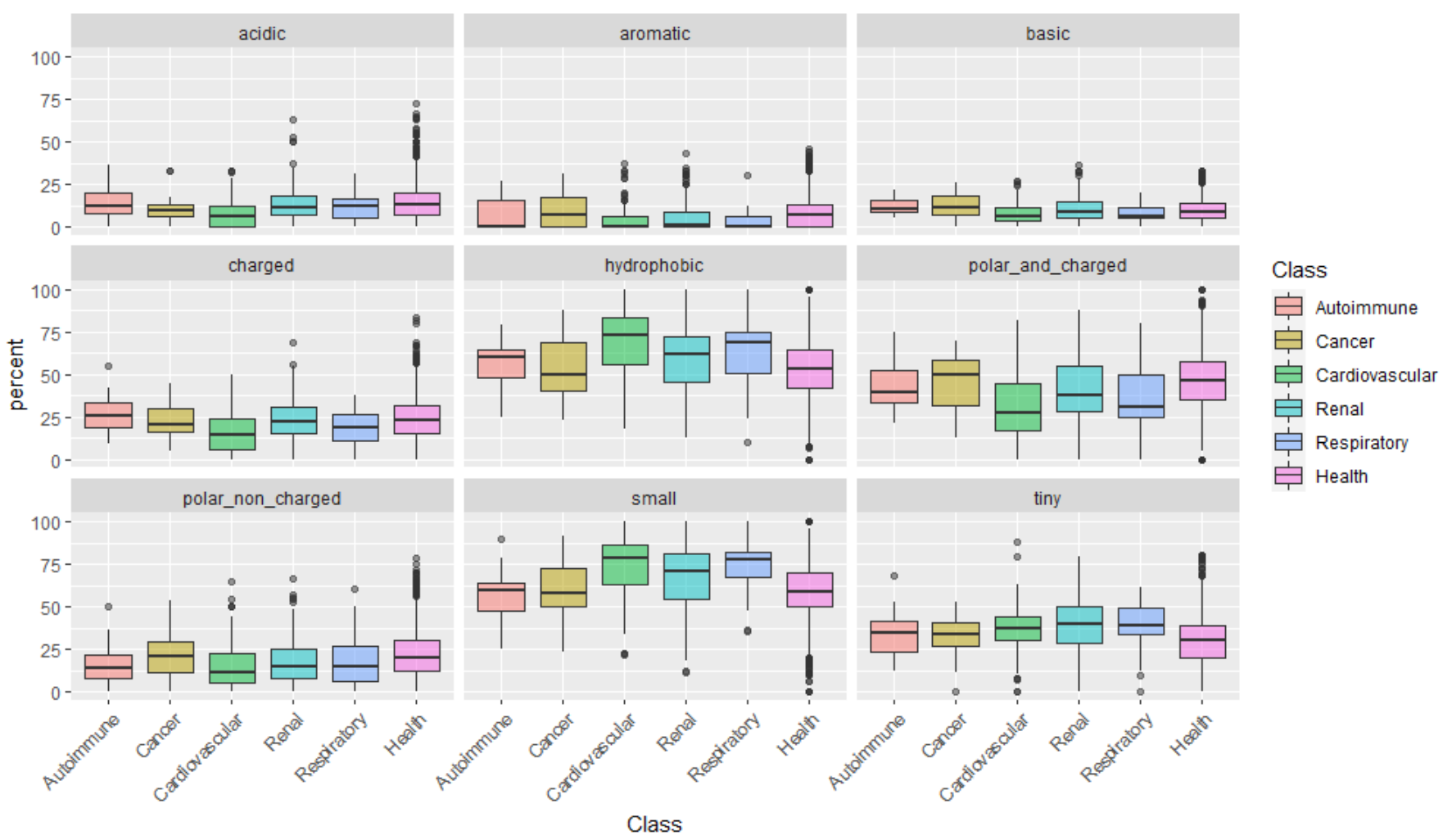

Figure 3. Composition of amino acid groups, according to physical-chemical properties (size, hydrophilicity/hydrophobicity, and isoelectric point) across the five main disease classes.

Nonetheless, surprisingly, a clear pattern of longer and heavier fingerprint peptides was found for cancer. Could the biological foundation of this observation reside on the operation of more stringent proteases, resulting in lesser cleavage events and, thus, in, averagely longer and heavier peptides? Alternatively (or concomitantly), is this the result of the inhibition of naturally active proteases? Due to the clinical potential, this topic deserves further investigation. Particularly, it would be important to assess if, for instance, in cancer risk models, the addition of the average peptide length or mass on top of clinical variables could improve the model's predictive power. Finally, the distribution of peptides according to the content in Pro, evidenced once more, the predominance of Pro-rich peptides in cardiovascular diseases. See, for instance, the large proportion of peptides composed of $40-60 \%$ Pro in cardiovascular conditions in Figure 4 . Whether this feature, complemented with clinical variables, might improve a cardiovascular condition's diagnosis through urinalysis remains to be confirmed in future studies focused on peptidome and amino acid composition analysis. 

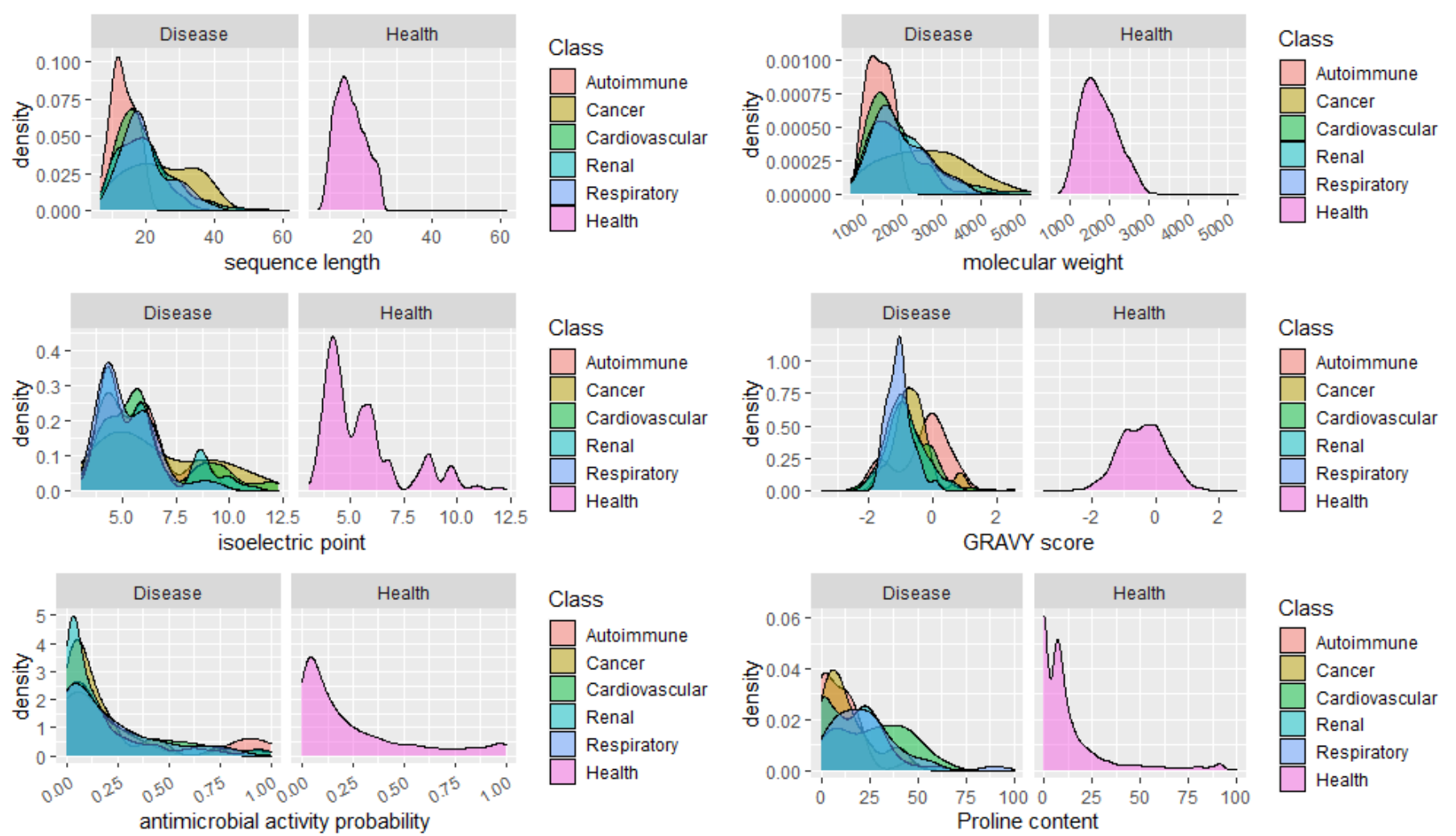

Figure 4. Density plots showing the distribution of peptides in health versus six main disease classes, regarding sequence length, molecular weight, isoelectric point, GRAVY score, antimicrobial peptide probability, and proline content.

\subsection{Can Proteases Help Distinguish Diseases?}

Glancing over the diversity of urinary peptides associated with unrelated pathologies, we hypothesized that predicting the most active proteases would give another layer of discrimination between such conditions. From over 550 proteases composing the human degradome, we predicted the activity of 74 proteases, from four different catalytic types: aspartic (4), cysteine (13), metalloproteases (22), and serine (35) proteases, acting on either the $\mathrm{N}$ - or C-termini of the urine proteins/peptides. We started by looking at the proteases which are more susceptible to dysregulation in disease. For such purpose, we computed the fold-enrichment over the proteases predicted to be active in health.

As depicted in Figure S1, we could not calculate the fold-enrichment for two serine proteases from the complete set of predicted proteases as these were only predicted in disease. These were the coagulation factor Xa (F10), responsible for converting prothrombin to thrombin, and the tryptase alpha (TPSAB1), a neutral protease present in mast cells. This analysis also evidences that metalloproteases are the most susceptible to dysregulation, remarkably stromelysin-2 (MMP10), which participates in extracellular matrix disassembly, for example, through fibronectin degradation. Following metalloproteases, serine proteases are the second class more prone to dysregulation, noticeably tripeptidyl-peptidase 1 (TPP1), a lysosomal protease acting mainly on hydrophobic proteins. Cysteine and aspartic proteases complete the list and are the enzymes least susceptible to activation or the proteases leading to minor changes in the urine peptidome in disease. Of note, only three proteases were predicted exclusively from the healthy peptidome: beta-secretase 1 (BACE1), an aspartic protease responsible for the proteolytic processing of amyloid precursor protein, plasma kallikrein (KLKB1), a serine protease with a key role in hemostasis, and trypsin-3 (PRSS3), a serine protease involved in digestion, among other processes. Whether their absence in the disease urine degradome is due to the increased expression of protease inhibitors remains to confirm. 
We hypothesized that different diseases and specific conditions would have distinct degradome profiles by looking at these preliminary data. To investigate this more in-depth, we used a similar strategy to gene ontology enrichment analysis to identify overrepresented proteases compared to health status. Proteases predicted in health were set as the reference library: 61,517 predictions from 3702 peptides, representing $98.2 \%$ of the initial peptide dataset. Concerning diseases, a total of 67,159 protease predictions could be made from 3001 peptides, representing $99.6 \%$ of all sequences initially identified. To identify which proteases were significantly enriched across diseases/classes, we performed a hypergeometric test and corrected for multiple testing by the Bonferroni method. Figure 5 shows the proteases predicted to be the most active in the various disease classes. We can see some proteases patterns according to the type of disease or the system affected by analyzing this plot. For instance, the aspartic protease gastricsin (PGC) is significantly enriched exclusively in autoimmune diseases. Serine proteases, remarkably hepsin (HPN), suppressor of tumorigenicity 14 (ST14), and transmembrane protease serine 6 (TMPRSS6) are significantly enriched in bowel diseases. Infections are characterized solely by serine proteases' dysregulation, namely TMPRSS6 and, more specifically, prothrombin (F2) and plasminogen (PLG), well-known hemostasis regulators. In turn, renal, cardiovascular, and metabolic diseases show pronounced dysregulation of metalloproteases, particularly of matrix metalloproteases. The activation of kallikrein-6 (KLK6) is exclusive of respiratory conditions. Perhaps due to cancer's heterogeneous nature, no clear profile of proteases was observed for this class. Nonetheless, the activation of the interstitial collagenase (MMP1) might be the result of the extracellular matrix disarray, an essential step for tumor invasion and metastasis [45]. Of note, cathepsin B (CTSB), a lysosomal protease involved in intracellular protein catabolism, is the only cysteine protease significantly enriched in disease (class level), but its activation is common to renal, cardiovascular, and metabolic conditions. For mental conditions as a main class, no overall protease enrichment was also evident.

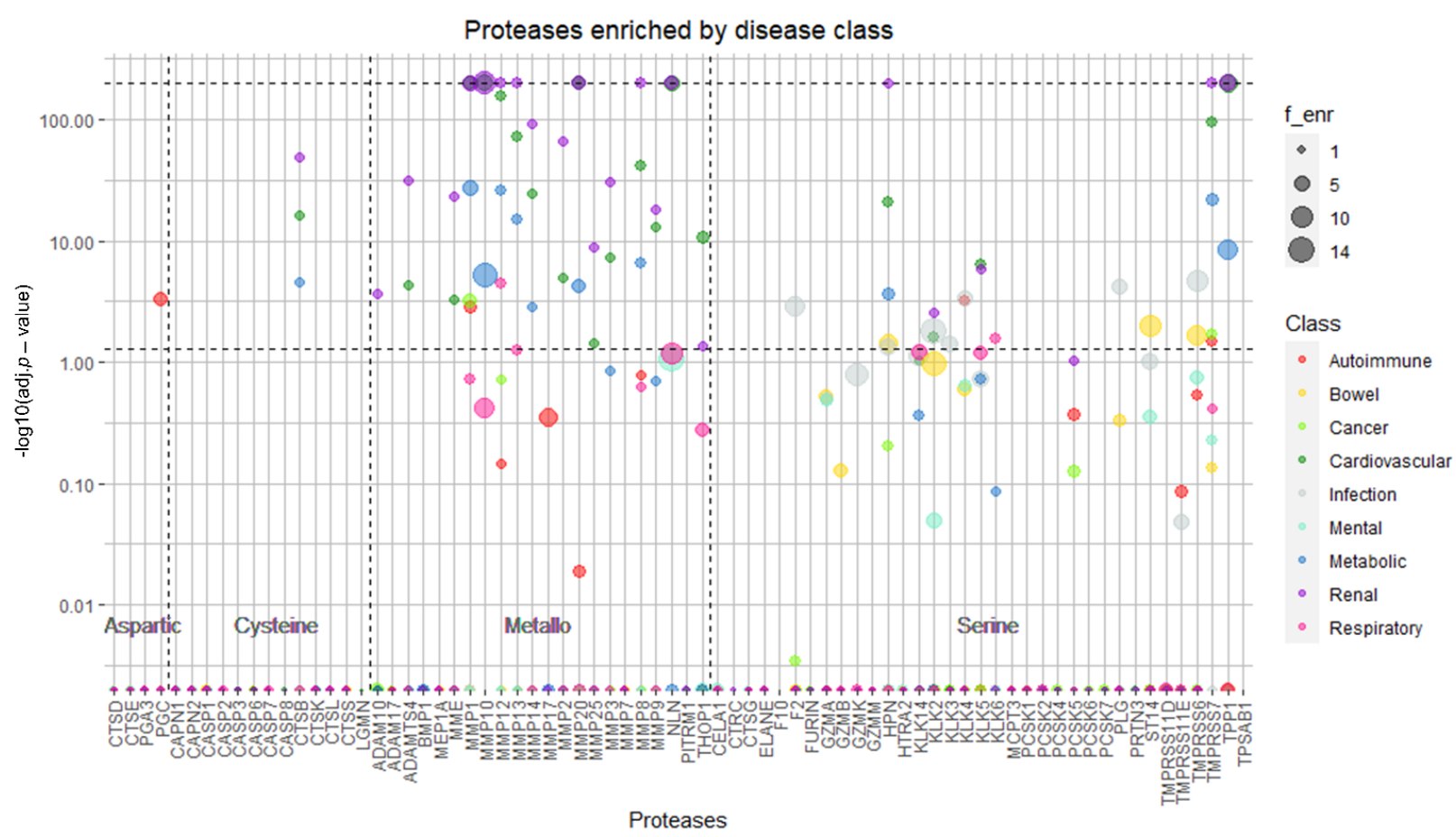

Figure 5. Protease fold-enrichment in the various disease classes: autoimmune (red), bowel (yellow), cancer (light green), cardiovascular (dark green), infection (grey), mental (cyan), metabolic (dark blue), renal (purple), and respiratory (pink) diseases. The size of the circles representing each protease is proportional to the magnitude of the enrichment. Proteases are arranged vertically according to the Bonferroni corrected $p$-value of the enrichment (hypergeometric test). The central horizonal line marks the significance threshold $(p=0.05)$. For representation purposes, proteases showing $-\log 10(p$-value) $>200$ were set to $-\log 10(p$-value $)=200$ and are represented on top of the upper horizonal line. 
The degradome signature of each disease is depicted in Figure 6. Proteases are sorted horizontally according to the catalytic class. Only proteases showing a significant enrichment are depicted. Each disease is clustered in a panel according to the respective class. This analysis shows that the protease profile increases our insight regarding differences between several conditions, showing exciting clinical potential. For instance, once again, MMP10 stands out as an overactive protease in many conditions, such as renal, metabolic, and cardiovascular diseases. This heatmap also highlights the activation of aspartic proteases in cancer. Also noteworthy is the almost exclusive activation of serine proteases in BK virus nephritis, as well as in necrotizing enterocolitis and in a chronic state of allograft nephropathy/dysfunction. Curiously, an end-stage renal disease in the setting of autosomal dominant polycystic kidney disease is mainly characterized by the activation of caspases.

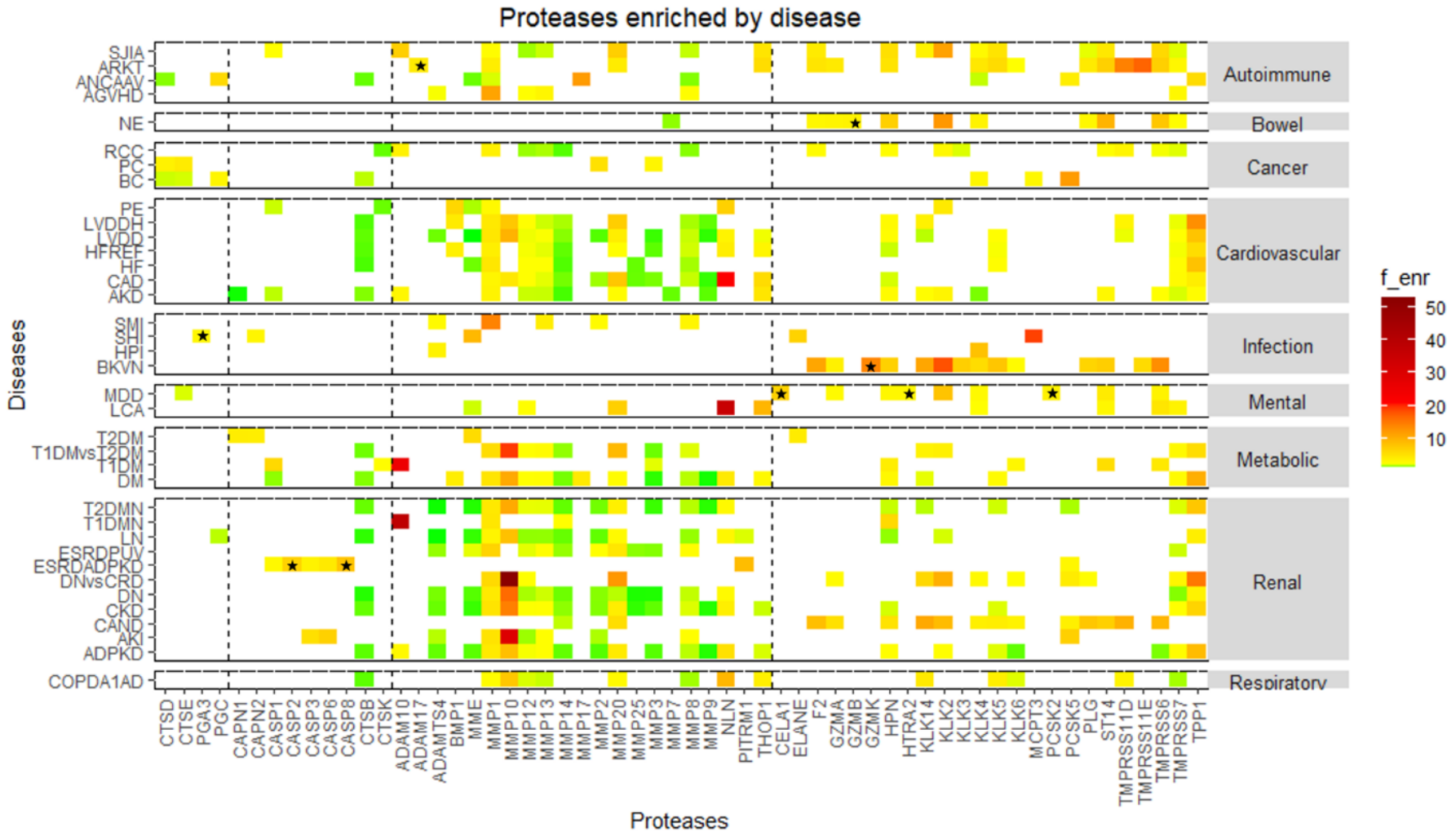

Figure 6. Heatmap showing significantly enriched proteases across specific conditions. Diseases are aligned vertically (please see abbreviations) according to the main class and proteases are aligned horizontally according to the catalytic class. A color code was set for fold-enrichment: 0-1 (under-representation), green; 1-10, yellow; 10-20, orange; 20-30, red; $>30$ dark red. Stars mark the unique proteases that are enriched exclusively in one disease.

Aiming at inspecting the specificity of the putative proteases to every disease at scope, we built a map with Cytoscape showing all significant associations as deemed by the hypergeometric test (the reader is referred to https:/ / public.ndexbio.org/\#/network/8c07b5f7 -a8e3-11eb-9e72-0ac135e8bacf?accesskey=653ffb5202553f1d3db97c4aeac15c0b1500efdf67e7 0f85a6d7b5478c3901c5) for an interactive exploration of each condition's putative degradome signature). Proteases (outer circle in the network) are arranged in a counterclockwise ascending spiral, highlighting an increasing specificity. Due to proteases' participation in many biological processes that are common to many pathological conditions, it is not surprising to verify that only seven out of 37 conditions included in this study can, theoretically, be identified by higher activity of a single protease. For instance, our analysis shows that F10 is explicitly dysregulated in Type 2 diabetic nephropathy. This comes with no 
surprise, given the association of diabetes with a hypercoagulable state of the blood and the fact that this protease has been pointed as a novel therapeutic target for this condition [46].

Another noteworthy observation is the overactivation of granzyme K (GZMK, 13.6fold enrichment) in BK virus nephritis. This may be explained by lymphocytes' activity, which releases granzymes to induce apoptosis of virus-infected cells, often resulting in collateral damage to noninfected tubule cells [47]. In turn, the association of caspase-2 (CASP2, 6.4-fold enrichment) and of caspase-8 (CASP8, 7.8-fold enrichment) activity with end-stage renal disease in the setting of the autosomal dominant polycystic disease has been confirmed in a rat model. It explains the activation of both the intrinsic and extrinsic pathways of apoptosis, a major hallmark of this disease [48]. The protease granzyme B (GZMB, 3.3-fold enrichment), which is also known for its role in stimulating apoptosis, was predicted exclusively from peptides associated with necrotizing enterocolitis, an association that has not yet been reported. According to our analysis, acute rejection of kidney transplant can also be monitored by assessing the activity of the protease disintegrin and metalloproteinase domain-containing protein 17 (ADAM17, 4.1-fold enrichment). ADAM17 has an important pro-inflammatory role in this condition, through shedding of tumor necrosis factor-alpha from its membrane-bound form as well as of its receptors [49]. Moreover, theoretically, a Schistosoma haematobium infection may be diagnosed by measuring the activity of urine pepsin A-3 (PGA3, 2.9-fold enrichment). PGA3 may be part of the protease armamentarium of this species that is essential to migrate through the host tissues, a common feature of many parasites [50]. Finally, a major depression disorder is putatively identified by the dysregulation of three proteases: neuroendocrine convertase 2 (PCSK2, 3.4-fold enrichment), the serine protease high temperature requirement protein A2, mitochondrial (HTRA2, 3.0-fold enrichment), and CELA1 (chymotrypsin-like elastase family member 1, 6.5-fold enrichment). PCKS2, for instance is, according to UniProt gene annotation, involved in processing prohormones and neuropeptide precursors, whose dysregulation might lead to depression.

Apart from these seven exceptions, we could sketch a minimal degradome fingerprint for many (21) of the remaining conditions (30), following the same rationale applied to peptides, where often these are integrated into multiplex panels to improve the accuracy of the diagnostic test. In Table 1, one can find the minimal combination of predicted proteases that identify a given disease, signatures which deserve further consideration in future biomarker studies. Even for the eight conditions that failed to show a specific degradome, the combination with specific peptides (Table S6) may be the key to develop a sensitive and specific diagnostic panel. Regardless of the nature of the biomolecules, peptides or proteases herein identified or predicted should, in principle, foster new avenues of research towards biomarker implementation in the era of 3PM [51]. 
Table 1. Putative minimal degradome signature for all conditions studied through urine peptidomics.

\begin{tabular}{|c|c|c|}
\hline Condition $^{1}$ & Class & Minimal Degradome Signature \\
\hline Type 2 diabetic nephropathy & Renal & $\mathrm{F} 10^{2}$ \\
\hline BK virus nephritis & Infection & GZMK or TPSAB1 ${ }^{2}$ \\
\hline $\begin{array}{l}\text { End-stage renal disease in the setting of autosomal } \\
\text { dominant polycystic kidney disease }\end{array}$ & Renal & CASP2 or CASP8 \\
\hline Necrotizing enterocolitis & Bowel & GZMB \\
\hline Acute rejection of kidney transplant & Autoimmune & ADAM17 \\
\hline Schistosoma haematobium infection & Infection & PGA3 \\
\hline Major depressive disorder & Mental & PCSK2, HTRA2 or CELA1 \\
\hline Acute Kawasaki disease & Cardiovascular & CAPN1 + MMP7 \\
\hline Bladder cancer & Cancer & CTSE + MCPT3 \\
\hline Lupus nephritis & Renal & PITRM1 + PGC \\
\hline Renal cell cancer & Cancer & KLK3 + CTSK \\
\hline Preeclampsia & Cardiovascular & CTSK + BMP1 \\
\hline Diabetes mellitus & Metabolic & $\mathrm{MMP} 17+\mathrm{BMP} 1$ \\
\hline Autosomal dominant polycystic kidney disease & Renal & KLK6 + MMP9 \\
\hline $\begin{array}{l}\text { Left ventricular diastolic dysfunction and } \\
\text { hypertension }\end{array}$ & Cardiovascular & BMP1 + TMPRSS11D \\
\hline Prostate cancer & Cancer & CTSE + MMP2 \\
\hline Helicobacter pylori infection & Infection & ADAMTS4 + KLK4 \\
\hline Diabetic nephropathy versus chronic renal disease & Renal & GZMA + MMP10 \\
\hline Acute kidney injury & Renal & $\begin{array}{c}\text { (CASP3 or CASP6) }+(\text { ADAMTS4 or } \\
\text { MMP2 })\end{array}$ \\
\hline $\begin{array}{l}\text { Anti-neutrophil cytoplasmic antibody-associated } \\
\text { vasculitis }\end{array}$ & Autoimmune & MMP17 + CTSD + PGC \\
\hline Type 2 diabetes mellitus & Metabolic & CAPN1 + CAPN2 + ELANE \\
\hline Type 1 diabetes mellitus & Metabolic & CTSK + ADAM10 + CASP1 \\
\hline Systemic juvenile idiopathic arthritis & Autoimmune & ADAM10 + CASP1 + F2 \\
\hline Left ventricular diastolic dysfunction & Cardiovascular & MMP9 + TMPRSS11D + THOP1 \\
\hline Chronic kidney disease & Renal & ADAMTS4 + MMP9 + MMP25 \\
\hline $\begin{array}{l}\text { Type } 1 \text { diabetes mellitus versus Type } 2 \text { diabetes } \\
\text { mellitus }\end{array}$ & Metabolic & KLK14 + KLK2 + MMP3 \\
\hline $\begin{array}{l}\text { Chronic obstructive pulmonary disease with } \\
\text { alpha-1-antitrypsin deficiency }\end{array}$ & Respiratory & TMPRS11D + KLK6 + NLN \\
\hline Chronic allograft nephropathy or dysfunction & Renal & GZMA + PCSK5 + (F2 or TMPRS11D $)$ \\
\hline
\end{tabular}

\section{Study Limitations}

Despite of the wealth of peptidome data compiled and reanalyzed in this paper, there are some limitations to acknowledge. First, we cannot appreciate the influence of demographic variables, such as age, sex, or ethnicity, or the effect of pharmacological treatments, in the different disease peptide profiles, as most, if not all, studies collected do not provide single patient peptide sequence profiles, nor their individual characteristics. Second, there are heterogeneities in the study design and in the instrumentation used, 
reflecting the large span of publication dates (2004-2020). Consequently, the number of peptides associated to any disease in older studies may be lower, biased by the lower resolution and sensitivity of the mass spectrometers available then. To circumvent this limitation, we restricted the physical-chemical analysis of the "signature" peptides to the disease classes showing higher number of associated peptides $(>20)$. Finally, we could only use one study to extract the reference healthy peptidome. In such a study, six urine sample from healthy individuals was analyzed, resulting in more than 4500 sequenced peptides. One should acknowledge, though, that many more urine peptides remain to identify, and that many of these peptides despite not directly associated with disease, can be present in the urine of ill patients. Therefore, the addition of new urine peptidome datasets of healthy individuals is expected to improve the peptidome and degradome profiles herein sketched.

\section{Conclusions}

In the everlasting quest of finding new and more specific disease biomarkers, either in a single or in a multiplex fashion, urine peptidomics and degradomics progressively occupy a relevant position in the most fruitful methodologic approaches. Urine is simultaneously a simpler biological matrix to uncover biomarkers, with less interfering substances than blood-derived products, and a depot of substances from the entire body, virtually allowing to monitor molecular alterations occurring as a consequence of any disease. Furthermore, the peptidome, while technically simpler to analyze, is more complex than the proteome, which may increase the odds for discriminating diseases based on a combination of analytes, not to mention that peptidomics is a good source of information for the characterization of the degradome-itself another source of surrogate markers.

The analysis of all peptidome datasets available today demonstrated its great potential towards biomarker discovery, as shown by the tenths of specific peptides for various conditions afflicting different systems, such as the renal, cardiovascular, pulmonary, and metabolic ones. These peptides are disclosed without reserve as supplementary material and their diagnostic potential merit further scrutiny. Moreover, our analysis suggests that peptides physical-chemical properties may themselves help improve the robustness of disease-predicting models. Particularly, it might be interesting in the future, to test the discriminatory value of proline content for cardiovascular diseases and the value of sequence length/mass for the diagnosis of cancer.

Finally, the present study shows that peptidomics is a double source of information, whose potential extends beyond the insight on dysregulated peptides, by allowing to unveil dysregulated proteases in disease, making use of predictive tools (Proteasix). The prediction of the degradome from the most comprehensive urine peptidome dataset reunited to date revealed a remarkable specificity of the granzymes B and K, caspases 2 and 8, pepsin A-3 and of the disintegrin and metalloproteinase domain-containing protein 17 , neuroendocrine convertase 2, serine protease HTRA2 (mitochondrial) and the chymotrypsin-like elastase family member 1 which were associated with a single condition. Furthermore, a specific degradomic signature combining no more than three proteases could be sketched for most of the enrolled conditions, whose validation is imperative. Ultimately, this study advocates the combination of a urine peptidomics-degradomics approach for the discovery and development of new biomarker panels regardless of the origin of the disease. These molecular patterns can potentially be used in any of the three main axes of 3PM, from predicting to preventing and personalizing medical treatment, with the great advantage of a noninvasive monitoring of the disease evolution or remission through a liquid biopsy.

Supplementary Materials: The following are available online at https:/ / www.mdpi.com/article/10 $.3390 /$ ijms22115940/s1.

Author Contributions: Conceptualization, R.V., F.T.; literature search and data curation, F.T., J.S., R.V.; methodology and data analysis, F.T., A.S.B., R.V.; original draft preparation, F.T., J.S., R.V.; critical review and editing, F.T., A.S.B., J.S., A.V., I.F.-P., S.G., C.V., R.F., A.L.-M., F.A., R.V. All authors have read and agreed to the published version of the manuscript. 
Funding: This research was funded by the Portuguese Foundation for Science and Technology (FCT), European Union, Quadro de Referência Estratégico Nacional (QREN), Fundo Europeu de Desenvolvimento Regional (FEDER) and Programa Operacional de Competitividade (COMPETE), through UnIC (UIDB/IC/00051/2020 and UIDP/00051/2020), iBiMED (UIDB/04501/2020, POCI01-0145-FEDER-007628) and LAQV-REQUIMTE (UIDB/50006/2020) research units. This study was also supported by the project "New targets in diastolic heart failure: from comorbidities to personalized medicine-NETDIAMOND", financed by the European Structural and Investment Funds (ESIF), through the Programa Operacional Regional Lisboa 2020 (POCI-01-0145-FEDER-016385) and national funds by FCT (SAICTPAC/0047/2015). R.V. is supported by an individual fellowship grant (IF/00286/2015). F.T. is a recipient of a post-doctoral research grant by UnIC (UIDP/00051/2020).

Institutional Review Board Statement: Not applicable.

Informed Consent Statement: Not applicable.

Data Availability Statement: All data generated or analyzed during this study is provided as supplementary files. Networks are deposited without reserve in NDex. The reader can explore the peptides and proteases associated with disease by following the links provided in the paper.

Conflicts of Interest: The authors declare no conflict of interest. The funders had no role in the design of the study; in the collection, analyses, or interpretation of data; in the writing of the manuscript, or in the decision to publish the results.

\begin{abstract}
Abbreviations
AGVHD: Acute graft-versus-host disease; AKD: Acute Kawasaki disease; AKI: Acute kidney injury; ARKT: Acute rejection of kidney transplant; ANCAAV: Anti-neutrophil cytoplasmic antibodyassociated vasculitis; ADPKD: Autosomal dominant polycystic kidney disease; BKVN: BK virus nephritis; BC: Bladder cancer; CAND: Chronic allograft nephropathy or dysfunction; CKD: Chronic kidney disease; COPDA1AD: Chronic obstructive pulmonary disease with alpha-1-antitrypsin deficiency; CAD: Coronary artery disease; DM: Diabetes mellitus; DN: Diabetic nephropathy; DNvsCRD: Diabetic nephropathy versus chronic renal disease; ESRDADPKD: End-stage renal disease in the setting of autosomal dominant polycystic kidney disease; ESRDPUV: End-stage renal disease in the setting of posterior urethral valves; HF: Heart Failure; HFREF: Heart failure with reduced ejection fraction; HPI: Helicobacter pylori infection; LCA: Low cognitive ability; LVDD: Left ventricular diastolic dysfunction; LVDDH: Left ventricular diastolic dysfunction and hypertension; LN: Lupus nephritis; MDD: Major depressive disorder; NE: Necrotising enterocolitis; PE: Preeclampsia; PC: Prostate cancer; RCC: Renal cell cancer; SHI: Schistosoma haematobium infection; SMI: Schistosoma mansoni infection; SJIA: Systemic juvenile idiopathic arthritis; T1DM: Type 1 diabetes mellitus; T1DMvsT2DM: Type 1 diabetes mellitus versus type 2 diabetes mellitus; T1DMN: Type 1 diabetic nephropathy; T2DM: Type 2 diabetes mellitus; T2DMN: Type 2 diabetic nephropathy.
\end{abstract}

\title{
References
}

1. Caron, E.; Aebersold, R.; Banaei-Esfahani, A.; Chong, C.; Bassani-Sternberg, M. A Case for a human immuno-peptidome project consortium. Immunity 2017, 47, 203-208. [CrossRef] [PubMed]

2. Gelman, J.S.; Fricker, L.D. Hemopressin and other bioactive peptides from cytosolic proteins: Are these non-classical neuropeptides? AAPS J. 2010, 12, 279-289. [CrossRef] [PubMed]

3. Lee, P.Y.; Low, T.Y.; Jamal, R. Probing the endogenous peptidomes of cancer for biomarkers: A new endeavor. In Advances in Clinical Chemistry; Elsevier: Cambridge, MA, USA, 2019; pp. 67-89. ISBN 0065-2423.

4. Sarkizova, S.; Klaeger, S.; Le, P.M.; Li, L.W.; Oliveira, G.; Keshishian, H.; Hartigan, C.R.; Zhang, W.; Braun, D.A.; Ligon, K.L.; et al. A large peptidome dataset improves HLA class I epitope prediction across most of the human population. Nat. Biotechnol. 2020, 38, 199-209. [CrossRef] [PubMed]

5. Lygirou, V.; Latosinska, A.; Makridakis, M.; Mullen, W.; Delles, C.; Schanstra, J.P.; Zoidakis, J.; Pieske, B.; Mischak, H.; Vlahou, A. Plasma proteomic analysis reveals altered protein abundances in cardiovascular disease. J. Transl. Med. 2018, 16, 104. [CrossRef]

6. Puente, X.S.; Sánchez, L.M.; Overall, C.M.; López-Otín, C. Human and mouse proteases: A comparative genomic approach. Nat. Rev. Genet. 2003, 4, 544. [CrossRef]

7. Lee, P.Y.; Osman, J.; Low, T.Y.; Jamal, R. Plasma/Serum proteomics: Depletion strategies for reducing high-abundance proteins for biomarker discovery. Bioanalysis 2019, 11, 1799-1812. [CrossRef] 
8. Golubnitschaja, O.; Baban, B.; Boniolo, G.; Wang, W.; Bubnov, R.; Kapalla, M.; Krapfenbauer, K.; Mozaffari, M.S.; Costigliola, V. Medicine in the early twenty-first century: Paradigm and anticipation-EPMA position paper 2016. EPMA J. $2016,7,23$. [CrossRef]

9. Latosinska, A.; Siwy, J.; Mischak, H.; Frantzi, M. Peptidomics and proteomics based on CE-MS as a robust tool in clinical application: The past, the present, and the future. Electrophoresis 2019, 40, 2294-2308. [CrossRef]

10. Di Meo, A.; Pasic, M.D.; Yousef, G.M. Proteomics and peptidomics: Moving toward precision medicine in urological malignancies. Oncotarget 2016, 7, 52460-52474. [CrossRef]

11. Greening, D.W.; Kapp, E.A.; Simpson, R.J. The peptidome comes of age: Mass spectrometry-based characterization of the circulating cancer peptidome. Pept. Cancer Deriv. Enzym. Prod. 2017, 42, 27-64. [CrossRef]

12. Schrader, M. Origins, technological development, and applications of peptidomics. In Peptidomics; Schrader, M., Fricker, L., Eds.; Springer: New York, NY, USA, 2018; pp. 3-39. ISBN 978-1-4939-7537-2.

13. Cai, T.; Yang, F. Strategies for characterization of low-abundant intact or truncated low-molecular-weight proteins from human plasma. Enzymes 2017, 42, 105-123. [CrossRef]

14. Klein, J.; Bascands, J.-L.; Mischak, H.; Schanstra, J.P. The role of urinary peptidomics in kidney disease research. Kidney Int. 2016, 89, 539-545. [CrossRef]

15. Štěpánová, S.; Kašička, V. Analysis of proteins and peptides by electromigration methods in microchips. J. Sep. Sci. 2016, 40, 228-250. [CrossRef]

16. Pontillo, C.; Mischak, H. Urinary peptide-based classifier CKD273: Towards clinical application in chronic kidney disease. Clin. Kidney J. 2017, 10, 192-201. [CrossRef]

17. Øverbye, A.; Skotland, T.; Koehler, C.J.; Thiede, B.; Seierstad, T.; Berge, V.; Sandvig, K.; Llorente, A. Identification of prostate cancer biomarkers in urinary exosomes. Oncotarget 2015, 6, 30357-30376. [CrossRef]

18. Markoska, A.; Valaiyapathi, R.; Thorn, C.; Dornhorst, A. Urinary C peptide creatinine ratio in pregnant women with normal glucose tolerance and type 1 diabetes: Evidence for insulin secretion. BMJ Open Diabetes Res. Care 2017, 5, e000313. [CrossRef]

19. Schanstra, J.P.; Zürbig, P.; Alkhalaf, A.; Argiles, A.; Bakker, S.J.L.; Beige, J.; Bilo, H.J.G.; Chatzikyrkou, C.; Dakna, M.; Dawson, J.; et al. Diagnosis and prediction of CKD progression by assessment of urinary peptides. J. Am. Soc. Nephrol. 2015, 26, 1999-2010. [CrossRef]

20. Pontillo, C.; Mischak, H. Urinary biomarkers to predict CKD: Is the future in multi-marker panels? Nephrol. Dial. Transplant. 2016, 31, 1373-1375. [CrossRef]

21. Tofte, N.; Lindhardt, M.; Adamova, K.; Bakker, S.J.L.; Beige, J.; Beulens, J.W.J.; Birkenfeld, A.L.; Currie, G.; Delles, C.; Dimos, I.; et al. Early detection of diabetic kidney disease by urinary proteomics and subsequent intervention with spironolactone to delay progression (PRIORITY): A prospective observational study and embedded randomised placebo-controlled trial. Lancet Diabetes Endocrinol. 2020, 8, 301-312. [CrossRef]

22. Markoska, K.; Pejchinovski, M.; Pontillo, C.; Zürbig, P.; Dakna, M.; Masin-Spasovska, J.; Stojceva-Taneva, O.; Mischak, H.; Spasovski, G. MO024 urinary peptide biomarkers associated with improvement in eGFR in CKD patients. Nephrol. Dial. Transplant. 2016, 31, i38. [CrossRef]

23. Van, J.A.D.; Scholey, J.W.; Konvalinka, A. Insights into diabetic kidney disease using urinary proteomics and bioinformatics. J. Am. Soc. Nephrol. 2017, 28, 1050-1061. [CrossRef]

24. Krochmal, M.; Kontostathi, G.; Magalhães, P.; Makridakis, M.; Klein, J.; Husi, H.; Leierer, J.; Mayer, G.; Bascands, J.-L.; Denis, C.; et al. Urinary peptidomics analysis reveals proteases involved in diabetic nephropathy. Sci. Rep. 2017, 7, 15160. [CrossRef] [PubMed]

25. Bustamante, C.J.; Kaiser, C.M.; Maillard, R.A.; Goldman, D.H.; Wilson, C.A.M. Mechanisms of cellular proteostasis: Insights from single-molecule approaches. Annu. Rev. Biophys. 2014, 43, 119-140. [CrossRef]

26. Andersen, H.; Friis, U.G.; Hansen, P.B.L.; Svenningsen, P.; Henriksen, J.E.; Jensen, B.L. Diabetic nephropathy is associated with increased urine excretion of proteases plasmin, prostasin and urokinase and activation of amiloride-sensitive current in collecting duct cells. Nephrol. Dial. Transplant. 2015, 30, 781-789. [CrossRef] [PubMed]

27. Madhusudhan, T.; Kerlin, B.A.; Isermann, B. The emerging role of coagulation proteases in kidney disease. Nat. Rev. Nephrol. 2016, 12, 94-109. [CrossRef] [PubMed]

28. De Boer, I.H. A New chapter for diabetic kidney disease. N. Engl. J. Med. 2017, 377, 885-887. [CrossRef] [PubMed]

29. Shi, S.; Koya, D.; Kanasaki, K. Dipeptidyl peptidase-4 and kidney fibrosis in diabetes. Fibrogenes. Tissue Repair $2016,9,1$. [CrossRef] [PubMed]

30. Padoan, A.; Basso, D.; Zambon, C.-F.; Prayer-Galetti, T.; Arrigoni, G.; Bozzato, D.; Moz, S.; Zattoni, F.; Bellocco, R.; Plebani, M. MALDI-TOF peptidomic analysis of serum and post-prostatic massage urine specimens to identify prostate cancer biomarkers. Clin. Proteom. 2018, 15, 23. [CrossRef] [PubMed]

31. Chinello, C.; Cazzaniga, M.; De Sio, G.; Smith, A.J.; Gianazza, E.; Grasso, A.; Rocco, F.; Signorini, S.; Grasso, M.; Bosari, S.; et al. Urinary signatures of renal cell carcinoma investigated by peptidomic approaches. PLoS ONE 2014, 9, e106684. [CrossRef] [PubMed]

32. Magalhães, P.; Pontillo, C.; Pejchinovski, M.; Siwy, J.; Krochmal, M.; Makridakis, M.; Carrick, E.; Klein, J.; Mullen, W.; Jankowski, J.; et al. Comparison of urine and plasma peptidome indicates selectivity in renal peptide handling. Proteom. Clin. Appl. 2018, 12, 1700163. [CrossRef] 
33. Sirolli, V.; Pieroni, L.; Di Liberato, L.; Urbani, A.; Bonomini, M. Urinary peptidomic biomarkers in kidney diseases. Int. J. Mol. Sci. 2019, 21, 96. [CrossRef]

34. Pejchinovski, M.; Siwy, J.; Mullen, W.; Mischak, H.; Petri, M.A.; Burkly, L.C.; Wei, R. Urine peptidomic biomarkers for diagnosis of patients with systematic lupus erythematosus. Lupus 2017, 27, 6-16. [CrossRef]

35. Nkuipou-Kenfack, E.; Bhat, A.; Klein, J.; Jankowski, V.; Mullen, W.; Vlahou, A.; Dakna, M.; Koeck, T.; Schanstra, J.P.; Zürbig, P.; et al. Identification of ageing-associated naturally occurring peptides in human urine. Oncotarget 2015, 6, 34106-34117. [CrossRef]

36. Zhang, Z.-Y.; Ravassa, S.; Nkuipou-Kenfack, E.; Yang, W.-Y.; Kerr, S.M.; Koeck, T.; Campbell, A.; Kuznetsova, T.; Mischak, H.; Padmanabhan, S.; et al. Novel urinary peptidomic classifier predicts incident heart failure. J. Am. Heart Assoc. 2017, 6, e005432. [CrossRef]

37. Siwy, J.; Mullen, W.; Golovko, I.; Franke, J.; Zürbig, P. Human urinary peptide database for multiple disease biomarker discovery. Proteom. Clin. Appl. 2011, 5, 367-374. [CrossRef]

38. Di Meo, A.; Bartruch, I.; Yousef, A.G.; Pasic, M.D.; Diamandis, E.P.; Yousef, G.M. An integrated proteomic and peptidomic assessment of the normal human urinome. Clin. Chem. Lab. Med. 2017, 55, 237. [CrossRef]

39. Osorio, D.; Rondon-Villarreal, P.; Torres, R. Peptides: A package for data mining of antimicrobial peptides. $R$ J. 2015, 7, 4-14. [CrossRef]

40. Klein, J.; Eales, J.; Zürbig, P.; Vlahou, A.; Mischak, H.; Stevens, R. Proteasix: A tool for automated and large-scale prediction of proteases involved in naturally occurring peptide generation. Proteomics 2013, 13, 1077-1082. [CrossRef]

41. Rawlings, N.D.; Barrett, A.J.; Thomas, P.D.; Huang, X.; Bateman, A.; Finn, R.D. The MEROPS database of proteolytic enzymes, their substrates and inhibitors in 2017 and a comparison with peptidases in the PANTHER database. Nucleic Acids Res. 2018, 46, D624-D632. [CrossRef]

42. Frantzi, M.; Metzger, J.; Banks, R.E.; Husi, H.; Klein, J.; Dakna, M.; Mullen, W.; Cartledge, J.J.; Schanstra, J.P.; Brand, K.; et al. Discovery and validation of urinary biomarkers for detection of renal cell carcinoma. J. Proteom. 2014, 98, 44-58. [CrossRef]

43. Van, J.A.D.; Clotet-Freixas, S.; Zhou, J.; Batruch, I.; Sun, C.; Glogauer, M.; Rampoldi, L.; Elia, Y.; Mahmud, F.H.; Sochett, E.; et al. Peptidomic analysis of urine from youths with early type 1 diabetes reveals novel bioactivity of uromodulin peptides in vitro. Mol. Cell. Proteom. 2020, 19, 501-517. [CrossRef]

44. Martin-Lorenzo, M.; Zubiri, I.; Maroto, A.S.; Gonzalez-Calero, L.; Posada-Ayala, M.; de la Cuesta, F.; Mourino-Alvarez, L.; Lopez-Almodovar, L.F.; Calvo-Bonacho, E.; Ruilope, L.M.; et al. KLK1 and ZG16B proteins and arginine-proline metabolism identified as novel targets to monitor atherosclerosis, acute coronary syndrome and recovery. Metabolomics 2015, 11, 1056-1067. [CrossRef]

45. Gobin, E.; Bagwell, K.; Wagner, J.; Mysona, D.; Sandirasegarane, S.; Smith, N.; Bai, S.; Sharma, A.; Schleifer, R.; She, J.-X. A pan-cancer perspective of matrix metalloproteases (MMP) gene expression profile and their diagnostic/prognostic potential. BMC Cancer 2019, 19, 581. [CrossRef]

46. Oe, Y.; Hayashi, S.; Fushima, T.; Sato, E.; Kisu, K.; Sato, H.; Ito, S.; Takahashi, N. Coagulation factor Xa and protease-activated receptor 2 as novel therapeutic targets for diabetic nephropathy. Arterioscler. Thromb. Vasc. Biol. 2016, 36, 1525-1533. [CrossRef] [PubMed]

47. Bohl, D.L.; Brennan, D.C. BK virus nephropathy and kidney transplantation. Clin. J. Am. Soc. Nephrol. 2007, 2, S36-S46. [CrossRef] [PubMed]

48. Tao, Y.; Kim, J.; Stanley, M.; He, Z.; Faubel, S.; Schrier, R.W.; Edelstein, C.L. Pathways of caspase-mediated apoptosis in autosomal-dominant polycystic kidney disease (ADPKD). Kidney Int. 2005, 67, 909-919. [CrossRef] [PubMed]

49. Wang, J.; Li, Z.; Al-Lamki, R.; Wang, J.; Zuo, N.; Bradley, J.R.; Wang, L. The role of tumor necrosis factor- $\alpha$ converting enzyme in renal transplant rejection. Am. J. Nephrol. 2010, 32, 362-368. [CrossRef]

50. McKerrow, J.H.; Caffrey, C.; Kelly, B.; Loke, P.; Sajid, M. Proteases in parasitic diseases. Annu. Rev. Pathol. Mech. Dis. 2006, 1, 497-536. [CrossRef]

51. Gerner, C.; Costigliola, V.; Golubnitschaja, O. Multiomic patterns in body fluids: Technological challenge with a great potential to implement the advanced paradigm of 3P medicine. Mass Spectrom. Rev. 2020, 39, 442-451. [CrossRef] 